Articles

2-2016

\title{
A Meta-Analysis of the Effects of Enrichment Programs on Gifted Students
}

Mihyeon Kim

College of William and Mary, mxkim3@wm.edu

Follow this and additional works at: https://scholarworks.wm.edu/articles

Part of the Educational Assessment, Evaluation, and Research Commons, and the Gifted Education Commons

\section{Recommended Citation}

Kim, Mihyeon, "A Meta-Analysis of the Effects of Enrichment Programs on Gifted Students" (2016).

Articles. 70.

https://scholarworks.wm.edu/articles/70

This Article is brought to you for free and open access by W\&M ScholarWorks. It has been accepted for inclusion in Articles by an authorized administrator of W\&M ScholarWorks. For more information, please contact scholarworks@wm.edu. 


\begin{abstract}
Although descriptions of enrichment programs are valuable for practitioners, practices, and services for gifted students, they must be backed by evidence, derived through a synthesis of research. This study examined research on enrichment programs serving gifted students and synthesized the current studies between 1985 and 2014 on the effects of enrichment programs. A total of 26 studies were included in this meta-analysis, and the findings show that enrichment programs had a positive impact on both gifted students' academic achievement $(g=0.96,95 \%$ $\mathrm{CI}=0.64-1.30$, under a random-effects model $)$ and socio-emotional development $(g=0.55,95 \%$ $\mathrm{CI}=0.32-0.79$, under a random-effects model). Regarding moderators of the effects, types of programs, and grade levels influenced both effect sizes of academic achievement and socioemotional development. The largest effect size was observed for summer residential programs in terms of academic achievement and for a combination of summer and academic year program in terms of socio-emotional development.
\end{abstract}




\section{A Meta-Analysis of the Effects of Enrichment Programs on Gifted Students}

Although a strong empirical foundation is required to advance educational practices, the literature concerning gifted education is still lacking comprehensive empirical studies to provide

guidance for educational policy and practices to serve gifted students (Plucker \& Callahan, 2014). Among the various practices, acceleration and enrichment have been used widely as program and curriculum models (Schiever \& Maker, 2003). Both acceleration and enrichment programs have served diverse gifted students based on conceptual knowledge; however, our knowledge on practices for gifted students is often ambiguous when determining their effectiveness. Particularly, research on enrichment programs is often provided without a clear description of the specific program being studied.

Despite examination of studies with experimental effects is meaningful for practitioners to determine usefulness of programs (Asher, 2003), there are limited meta-analytic studies about the effects of enrichment programs on gifted students. Statistical significance alone is not a guarantee of practical usefulness, and effect size allows researchers and practitioners to look at the magnitude of the obtained difference between the sample mean and the hypothesized population mean (Warner, 2008). Asher (1986, 2003) noted that meta-analysis, which examines effect size strength rather than statistical significance, helps researchers and practitioners to understand the results of various studies better.

Kulik and Kulik (1984) completed a meta-analysis related to ability grouping in secondary schools, and they found that when high-ability students were grouped together in enrichment classes, it had positive impacts on their intellectual progress. Also, Vaughn, Feldhusen, and Asher (1991) conducted a meta-analysis on gifted pull-out programs and found 
positive impacts on achievement outcomes. Because all of the studies except one were published before 1985, there is little overlap between Vaughn et al.'s meta-analysis and current metaanalysis on the effects of enrichment programs for gifted students. Only one study from the meta-analysis of Vaughn et al. is included in this study.

Recently, Steenbergen-Hu and Moon (2011) published a meta-analysis on the effects of acceleration; they specifically defined acceleration as "a type of educational intervention based on progress through educational programs either at rates faster than or at ages younger than one's peers" (p. 39). Because the focus of their study was on the effects of acceleration, there was no overlap between the studies included there and the current study.

As discussed, previous studies are heavily based on effects of accelerated programs or grouping of gifted students rather than examining the effects of enrichment programs. In addition, meta-analysis that reviews on effects of enrichment programs needed to be updated with more current studies as shown by Vaughn et al.'s (1991) meta-analysis.

This study uses meta-analysis to synthesize the findings of studies related to enrichment programs for gifted students. It is intended to answer the following major questions about such programs:

1. What are the effects of enrichment programs on the socio-emotional development of gifted students?

2. What are the effects of enrichment programs on the academic achievement of gifted students?

3. How do different grade levels influence the effects of enrichment programs on both academic achievement and socio-emotional development? 
4. How do different program types influence the effects of enrichment programs on both academic achievement and socio-emotional development?

\section{Conceptual and Operational Definitions}

\section{Enrichment Programs}

Among various programs aimed at fulfilling the needs of gifted students, enrichment programs promote higher levels of thinking and creativity in a subject area and allow students to explore that subject in depth (Fox, 1979). Historically, during early years of gifted education, acceleration is the main accommodation for gifted students. However, acceleration raised concerns about addressing socio-emotional needs of gifted students. Therefore, educators in gifted education became interested in enrichment programs as a way of an accommodation to address both academic and socio-emotional needs of gifted students (Kulik, 1992).

Enrichment programs is to provide exploratory activities, in-depth materials on a topic, materials for the development of higher level thinking processes and skills, self-selected independent projects, or authentic products or services for a real-world audience (Fiddyment, 2014; Renzulli \& Reis, 1997). Enrichment programs have emphasized the importance of profound knowledge and skills within a subject to develop students' higher mental processes and creative production. To evaluate the effects of various enrichment programs, researchers have explored academic achievement, attitude toward the subject, and career-related motivation (Lee, Olszewski-Kubilius, \& Peternel, 2010; Markowitz, 2004; Reis \& Boeve, 2009; Stake \& Mares, 2001; Walsh, Kemp, Hodge \& Bowes, 2012). In this study, an enrichment program or enriched curriculum in this study refers to programs or curriculum that have modified content with more depth or breadth than generally provided or that have a modified process to develop a students' 
higher intellectual thinking and to provide opportunities for creative production (Schiever \& Maker, 2003).

Whereas, acceleration is defined as an educational intervention based on the mastery of higher grade level knowledge than typical grade level content, or speeding up the pace of material presented, enrichment provides richer and more varied content through modification and supplementation of content in addition to standard content in the regular classroom (Schiever \& Maker, 2003). Enrichment programs with suitable curricula for gifted students may provide opportunities for optimal development of their talents. Researchers have proposed enrichment programs as a way of nurturing social and behavioral skills as well as academic skills (Hynes, O'Connor, \& Chung, 1999; Schacter, 2001), and the literature on enrichment programs for gifted students includes suggested best practices to serve those students throughout different grade levels (Miller \& Gentry, 2010; Olszewski-Kubilius \& Lee, 2004; Olszewski-Kubilius \& Limburg-Weber, 1999). The term enrichment is often used in practice without a clear definition; however, this study explored the distinct effects of enrichment programs separated from the effects of acceleration programs in order to help researchers and practitioners to better understand the results of various program effects.

\section{Academic Achievement}

Academic achievement is one of the most critical outcome variables in educational research, ranging from global indicators, such as postsecondary attainment and school GPA, to some specific indicators, such as standardized test scores in a specific disciplinary area or quality of a specific performance (Fan \& Chen, 2001). Based on the literature reviewed in this study, various academic achievements are measured at the $\mathrm{K}-12$ level, including thinking processes, 
GPA, standardized test scores, specific types of intelligence, such as a creative thinking skills, and the quality of a specific performance. Outcomes from different subject areas, such as math, language arts, science, and so forth, are included under one category of academic achievement in this study.

\section{Socio-emotional Development}

Many researchers in gifted education have explored the affective development of students, and they have noted that social and emotional competence is a good predictor of success in life (Gardner, 1983; Goleman, 1995; Hébert, 2011). Many of the studies on enrichment programs also examined the effects of social and emotional development on gifted students. Issues related to the social and emotional development of gifted students often comprise special-populationrelated issues (e.g., identity or environmental effects), developmental issues (e.g., characteristics, gender related issues, locus of control, completion, perfectionism, self-concept, self-esteem, moral development), relationship issues (e.g., relationships with peer, family, or teachers), and school-related issues (e.g., academic planning, career planning; Clark, 2013; Cross \& Cross, 2012). Most often, self-reported questionnaires are used to measure socio-emotional development, including self-concept, career aspiration in a specific disciplinary area, self-esteem, relationships among peers and family, attitude toward school or peers, and motivation toward academics. Outcomes from different socio-emotional development issues are included under one category of socio-emotional development in this study.

\section{Methods}


In this meta-analysis, an enrichment program for gifted students is defined as organized educational activities beyond regular class activities that: (a) occurred during the school year or summer; (b) were organized to serve gifted students; and (c) were supervised by adults.

\section{Inclusion and Exclusion Criteria}

The following criteria for including studies were used in this study:

- Studies should have indicated a practice of enrichment programs for $\mathrm{K}-12$ gifted students. Studies on talent search programs are included in this meta-analysis only if they had components of an enrichment curriculum. Talent search programs identify students using off-level or above-grade-level tests and provide accelerated educational opportunities to meet gifted students' academic needs (Lee, Matthews, \& OlszewskiKubilius, 2008). This study included talent search programs if the programs specified an enrichment component, adjusting the content with depth and expanding learning experiences within the topic rather than focusing on mastering content faster mode. Programs providing accelerated educational opportunities were excluded. For example, talent search programs that used curriculum compacting were excluded. The student population of studies had to be indicated as gifted students. Studies outside of gifted education were included if they focused on enrichment courses or programs for gifted students. Although programs were developed to meet the needs of gifted students, studies about programs for all students were excluded. Many enrichment programs did not specify that the programs were for identified gifted students. For example, the Schoolwide Enrichment Program Model (SEM) was developed to serve gifted students; however, many studies that focused on the SEM practiced not for specifically gifted students. 
- In the current study, while enrichment refers to educational experiences with modified curriculum providing in-depth materials on a topic and materials for the development of higher level thinking processes and skills for greater depth and breadth of the content, acceleration indicates learning faster pace through academic content resulting in learning beyond standard grade level (Davis, Rimm, \& Siegle, 2011; Fiddyment, 2014; Renzulli \& Reis, 1997).

- All studies were published or reported during or after 1985. The publications included peer-reviewed journal articles, dissertations, and research technical reports.

- For purposes of the meta-analysis, studies included sufficient quantitative information for calculation of effect sizes (Cooper, 1998).

- Studies having control groups and treatment groups to compare were included in this meta-analysis. Also, studies having pre-and post-measurement were included in this study.

- Studies from outside the United States published in English were included in the search. 26 studies met the criteria for inclusion, 13 studies with academic achievement outcomes, and 16 studies with socio-emotional outcomes. Among the included studies, 3 studies included both academic and socio-emotional outcomes. In addition, 2 studies with socio-emotional outcomes produced two different grade level outcomes.

\section{Locating Relevant Studies}

Four procedures were used to locate articles during May and June in 2014 and April and May in 2015: (a) computer searches of multiple databases (Dissertations and Theses, Education Research Complete, ERIC, and PsycINFO); (b) hand searches of the contents of five journals with articles related to gifted students (Journal for the Education of the Gifted, Journal of 
Secondary Gifted Education, Gifted Child Quarterly, Roeper Review, and Journal of Advanced

Academics); (c) inspection of the references of each article; and (d) web searches using the

Google and Google Scholar search engines. One hundred and nine studies were selected for the inclusion decision, and only 26 studies met the inclusion criteria.

<Insert Figure 1 here>

\section{Coding of Studies}

A coding protocol was created to reflect information about the major characteristics of the study; experimental conditions, if any; setting of the study; participants and samples; and predictor and outcome characteristics (Cooper, 2011). Codes were left blank when the studies did not contain enough information.

Study characteristics. Each entry for a study began with the name of the first author and the year of publication. Then, the type of the study was coded as a journal article, dissertation, internal evaluation, or external evaluation.

Research design. The major research design feature was related to the nature of the comparison groups. Two types of comparisons were identified as pre- and post-comparison and as treated and control group comparison. The effect sizes were calculated with provided statistical information in the literature.

Student characteristics. Students were distinguished by grade levels. Grade levels of students were coded using three categories: elementary (K-5), middle (6-8), and high (9-12). When an independent sample overlapped two categories, the category with the greater number of grade levels was chosen.

Program Type. Program type included the nature of program (e.g., summer day program, residential program), and programs were coded using five categories: summer day programs, 
summer residential programs, academic year programs, academic year Saturday programs, and combinations of summer and academic year programs.

Outcome measures. Outcome measures were categorized as academic achievement outcome and socio-emotional outcome. A wide variety of knowledge and skill areas were measured for each enrichment program. Specific subject-matter outcomes and academic skillrelated outcomes were considered as the academic achievement outcome. Self-concept, selfesteem, career-related outcome, motivational outcome, and attitudes toward specific subject matters were considered as the socio-emotional outcome. The effect sizes of study samples were computed to assess the consistency of effect across studies, and to compute a summary effect of all included studies.

\section{Effect Size Calculation}

An effect size is a measure of the strength and direction of a relationship between variables, and the effect size metric used in this study was the $d$-index, or standardized mean difference measure, which is used to express the differences between two group means (Cooper, 2010). If the comparison involved a single sample tested pre- and post-measurement, the $d$ index was calculated to express the differences between pre and post means. Then, the $d$-index was converted to Hedges' $g$, which is the corrected standardized mean difference between two groups based on the pooled, weighted standard deviation so that it modifies effect sizes for small sample sizes (Rosenthal, 1991). For studies with pre- and post-measurements but without correlation information, correlations were computed from the standardized mean difference. For studies with dichotomous outcomes, log odds ratio was used as the effect size measure for dichotomous outcomes. While effect sizes are extracted, Hedges' $g$ was also calculated. The CMA software (Borenstein, Hedges, Higgins, \& Rothstein, 2006) provided various effect size 
formats including log odds ratio for every effect size so that change from one effect size format to another format was possible.

Effect sizes or sub-effect sizes were calculated for all of the outcome variables in the studies. If a single study contained more than one effect size, the average of these results was calculated to represent the study (Cooper, 2010). Because there are not enough studies for analysis of each different content area in academic achievement, such as English, math, and science, and different socio-emotional development aspects like friendship, self-concept, and career aspiration, this study analyzed in a broader sense on all academic achievement and on all socio-emotional developmental assessments.

This study synthesized two types of design of pre-post comparisons with a single group and comparisons between treatment groups and control groups. Effect sizes from different studies were combined through the CMA software (Borenstein et al., 2006). A random-effects model was chosen in this study to reflect variation of the true effect sizes among studies. Fixedeffects analysis assumes that the true effect size is the same in all studies; however, randomeffects analysis is used to assign weights to the different studies based on sample sizes. The random-effect model reflects sampling errors and estimates the mean of a distribution of effects rather than to estimate one true effect as fixed-model does (Borenstein, Hedges, Higgins, \& Rothstein, 2009).

\section{Heterogeneity Analysis}

A heterogeneity analysis is a common approach in meta-analysis. It examines how probable it is that the variance exhibited by the effect sizes would be observed if only sampling error was making them different (Cooper, 2010). A homogeneity statistic is associated with $p$ value of .05 , which means that only 5 times in 100 would sampling error create this amount of 
variance in effect sizes. A set of homogeneity is calculated through the CMA software using the $Q$ statistic to test whether the average effects from the two groupings are homogenous. If the $Q$ statistic exceeds the critical value, then the factor is a significant contributor to variance in effect sizes, and the homogeneity hypothesis is rejected. It reveals that the population of effect sizes is heterogeneous, meaning different effects have been observed for different groups (Cooper, 2010; Ellis, 2011).

To identify variables that moderate the effect of enrichment programs on gifted students, meta-regression was used. $Q$ statistic indicates the variations between/among subgroups of the effect sizes when these effect sizes are grouped by a certain variables to assess the relative impact of various measurement and contextual moderators. Statistically significant differences between the group means would indicate that the effects of enrichment programs are moderated by defined subgroups (Ellis, 2011; Steenbergen-Hu \& Moon, 2011).

\section{Results}

Separate meta-analyses were conducted for studies with academic achievement and socio-emotional outcomes, and involved four steps: (a) computation of an effect size for each research study; (b) computation of an overall effect size across research studies; (c) homogeneity analysis; and (d) moderator analysis. Comprehensive Meta-Analysis, a stand-alone software program, was used to analyze the data. This study reports Hedges $g$ as the measure of effect sizes, which Comprehensive Meta-Analysis assesses (Rosenthal, 1991). Hedges' $g$ provides information about the size of an effect in terms of standard deviation units. For example, a score of 1.0 means the difference is equal to one standard deviation, and a score of .25 means that the difference between the two groups is equivalent to one quarter of a standard deviation. Therefore, the bigger score has the bigger effect. Reporting effect sizes in standardized terms is useful for 
making comparisons across studies because the results are scale-free (Ellis, 2010). The effect size or sizes from each study were weighted by sample size based on the general assumption that studies with larger sample sizes produce more reliable estimates of effects.

A total of 26 studies out of 109 studies on effects of enrichment programs for the gifted met the inclusion criteria. Reasons for not meeting the criteria were lack of statistical data, no K12 population (e.g., college students), no indication of an identified gifted population, and a focus on teacher behavior change from trainings for enrichment programs rather than student outcomes. For academic achievement, the most common outcome variables in the studies were standardized achievement test results, measuring academic skills, quality of products, level of metacognition, and GPA. For social-emotional development, the most widely studied variables were self-concept, self-esteem, academic attitude and motivation, self-confidence, relationship, and career aspiration.

\section{Academic Achievement Studies}

Table 1 describes the characteristics of the 13 studies in the synthesis. Two studies examined enrichment programs implemented during summer (residential and day programs), nine studies examined enrichment programs during school hours, and two studies examined enrichment programs during both summer and the academic year. This study computed effect sizes based on 13 studies that reported group comparison or pretest-posttest difference scores. All of the studies focused on gifted students even though each study defined giftedness on the basis of different measurements.

<Insert Table 1 here>

Meta-analysis of academic achievement studies. Effect sizes for each of 14 independent samples were yielded from 14 studies. Table 2 presents information on each 
independent sample, including grade level, the effect size for the study, and the lower and upper limits of the $95 \%$ confidence interval for the effect size. For academic studies, Figure 1 provides a graphic display of each of the 14 effect sizes and their confidence interval as reported in Table

2.

<Insert Table 2 here>

$<$ Insert Figure 2 here>

Figure 1 indicates an overall tendency toward positive effects of enrichment programs on the academic achievement of gifted students. The average effect size overall based on a randomeffects model is .96 . The $95 \%$ confidence intervals around these effect sizes do not include zero, ranging from 0.64 to 1.30 , which supports the conclusion that the enrichment programs that were examined through this meta-analysis had a significantly positive effect on the academic achievement of gifted students $(p<.001)$. The homogeneity analysis for the academic achievements resulted in a $Q$ value of $85.32(p<.001)$, indicating statistically significant variation among the effect sizes.

The assessment of publication bias for the meta-analysis of academic achievement was performed on the 14 studies in this group. A funnel plot was produced for a visual inspection of publication bias. Although the majority of the studies appeared symmetrically around the mean effect line of the funnel plot, three studies were in the right part of the funnel. This might suggest the presence of publication bias. Duvall and Tweedie's trim-and-fill procedure was conducted, and still suggested the presence of publication bias. Statistics showed that under the random-effects model, the point estimate and the $95 \%$ confidence interval for the combined effects was $0.96(0.64,1.29)$, whereas after the trim-and-fill procedure, the combined effects 
became $1.06(0.71,1.41)$. This implied that the original combined effect size may be underestimated.

Studies with extremely high effect sizes were more intensive programs than other studies. For example, a study of Lynch and Mills (1990) produced highest effect size of 2.94, and their program consisted of yearlong programs made up of a combination of academic year and summer programs. Although there is no specific information about how many academic session hours were involved, two programs were intensive academic summer programs compared to other programs, which were academic year day programs. Another intensive program was facilitated by the Ministry of Education in the Kingdom of Saudi Arabia in cooperation with a number of centers for the gifted. This finding confirmed an existing perception that more intensive enrichment programs influence more academic achievement of gifted students.

Moderator analyses of academic achievement. Table 3 presents the mean effect sizes for each level of the different moderators, including the program type and grade level. In Table 3 , when the $95 \%$ confidence interval does not include zero, the effect size of the moderator is significantly different from zero. Table 3 also includes $Q$ values for heterogeneity analyses among the effect sizes that measure how each moderator influences the variation among the effect sizes for the studies. The effect sizes of elementary, middle, and high school gifted students were significantly greater than zero $(.57,1.37$, and 2.02 , respectively). The $Q$ values for grade levels were statistically different from zero. Among the studies, the largest effect size was observed for high school gifted students (2.02), followed by the effect size for middle school gifted students (1.37) and elementary school gifted students (.57).

For the moderator of types of program, the effect size of summer day programs was significantly different from zero, with an effect size of 0.76 . The $Q$ value was statistically 
significant, indicating that types of programs influenced effect sizes. Even though the largest effect size was observed for summer day programs and summer residential programs (2.02 and 2.68 , respectively), fewer number of effect sizes were included in the analysis compared to other types of enrichment programs.

In examining the types of qualitative measures as a moderator, the effect sizes of both the treatment and control group comparison and the pre-post comparison were significantly different from zero, with average effect sizes of 1.06 and .79, respectively. However, the $Q$ value was not statistically significant, indicating that the types of study did not influence effect sizes.

\section{Socio-Emotional Outcomes}

<Insert Table 3 here>

Table 4 describes the characteristics of the 16 studies in the synthesis and indicates whether studies examined socio-emotional outcomes. Nine studies examined enrichment programs implemented during summer (residential and day programs), and nine studies examined enrichment programs during school hours. Two studies produced two different grade level outcomes so that a total 18 socio-emotional outcomes were produced from 16 studies. The current study computed effect sizes based on these 16 studies that reported group comparison or pretest-posttest difference scores. All of the studies concerned gifted students even though each study defined giftedness on the basis of different measurements. This study computed effect sizes based on 11 studies that reported score gains or pretest-posttest difference scores, and seven studies reported group comparison results based on posttest scores.

<Insert Table 4 here>

Meta-analysis of socio-emotional outcomes. Effect sizes for each of 18 effect sizes were yielded from 16 studies. Table 5 presents information on each independent sample, 
including grade level, the effect size for the study, and the lower and upper limits of the $95 \%$ confidence interval for the effect size.

\section{$<$ Insert Table 5 here> \\ $<$ Insert Figure 3 here>}

Figure 2 indicates an overall tendency toward positive effects of enrichment programs on the socio-emotional outcome of gifted students. The average effect size overall based on a random-effects model is .55. The 95\% confidence intervals around these effect sizes do not include zero, ranging from .32 to .79 , which supports the conclusion that the enrichment programs that were examined through this meta-analysis had a significantly positive effect on the socio-emotional outcome of gifted students $(p<.001)$. The homogeneity analysis for the socioemotional outcome resulted in a $Q$ value of 253.74 ( $p<.001$ ), indicating statistically significant variation among the effect sizes.

The assessment of publication bias for the meta-analysis of socio-emotional development was performed on the 18 effect sizes from the 16 studies in this group. A funnel plot was produced for a visual inspection of publication bias. The majority of the studies clustered asymmetrically in the bottom part of the funnel. This might suggest the presence of publication bias. It could also indicate that studies with small numbers of participants were a major contributor in this meta-analysis. This finding suggests that research on enrichment programs for gifted education need more studies with more participants. Duvall and Tweedie's trim-and-fill

procedure was conducted, and still suggested the presence of publication bias. Statistics showed that under the random-effects model, the point estimate and the $95 \%$ confidence interval for the combined effects was $0.55(0.32,0.79)$, whereas after the trim-and-fill procedure, the combined 
effects became $0.81(0.48,1.15)$. This implies that the original combined effect size may be overestimated.

A study of Byne and Butler (2000) showed an extremely high effect size $(g=12.73)$ than other studies. Small sample size of 20 (10 each treatment and control groups) with quasiexperimental study design may cause this high extremely effect size contributing overestimating overall combined effect size.

Moderator analyses of socio-emotional outcomes. Table 3 presents the mean effect sizes for each level of the different moderators, including the program type and grade level. In Table 3, when the $95 \%$ confidence interval does not include zero, the effect size of the moderator is significantly different from zero. Table 3 also includes $Q$ values for homogeneity analyses among the effect sizes that measure how each moderator influences the variation among the effect sizes for the studies.

Table 6 presents the mean effect sizes for each level of the different moderators, including the types of program, types of study, and grade level. In Table 6, when the 95\% confidence interval does not include zero, the effect size of the moderator is significantly different from zero. Table 6 also includes $Q$ values for heterogeneity analyses among the effect sizes that measure how each moderator influences the variation among the effect sizes for the studies. The effect sizes of elementary, middle, and high school gifted students were significantly greater than zero $(.43, .93$, and .29 , respectively). $Q$ value for grade levels was statistically different from zero. Among the studies, the largest effect size was observed for middle school gifted students (.93), followed by the effect sizes for elementary school gifted students (.44) and elementary school gifted students (.29). 
For the moderator of types of program, the $Q$ value was statistically significant, indicating that types of programs influenced effect sizes. As indicated in Table 6, there was no effect size reported related to the effects of a combination of summer programs and academic year programs as well as academic-year Saturday programs on socio-emotional outcomes. The largest effect size was observed for summer residential programs (.74), followed by the effect sizes for academic-year in-school programs (.50) and summer day programs (.20).

In examining the types of studies as a moderator, the effect sizes of both the treatment and control group comparison and the pre-post comparison were significantly different from zero, with average effect sizes of .54 and .57 , respectively. The $Q$ value was statistically significant, indicating that the types of study influenced effect sizes.

$<$ Insert Table 6 here>

\section{Discussion and Implications}

The effectiveness of enrichment programs differs depending on whether the students' outcome is academic achievement or socio-emotional. Even though more studies explored the impact on socio-emotional outcomes than academic achievement, grade level and program period were statistically significant moderators of effect sizes for both academic achievement and socio-emotional outcomes.

As previous meta-analyses on pull-out and acceleration programs supported positive impacts on academic achievements, findings from this study also support the belief that enrichment programs can have positive effects on the achievement of gifted students (Steenbergen-Hu \& Moon, 2011; Vanghn et al., 1991). Also, results of this study on socioemotional development were consistent with the results of the meta-analyses on acceleration. However, the current study was not consistent with the results from Vaughn et al.'s (1991) study 
on socio-emotional aspects. According to Vaughn et al. (1991), there is no statistically significant impact of pull-out programs on gifted students' socio-emotional development. A possible explanation for this result is that the study explored only self-concept among various socio-emotional aspects whereas the current study and Steenbergen-Hu and Moon's (2011) study synthesized all different socio-emotional aspects with an overall effect size. Therefore, more studies need to be conducted to explore effects of separate factors within socio-emotional development.

Several factors influence the interpretation of the overall effect sizes. Although enrichment programs influenced academic achievement the most at the high school level, only one study with a high school population was included in this analysis. Many gifted high school students takes college-level courses through AP and dual enrollment, which are acceleration programs, so not many studies have been done to assess the effectiveness on academic achievement of enrichment programs in high schools. Although a meta-analysis on acceleration programs compared between grade-based acceleration and content-based acceleration, which showed no statistical differences (Steenbergen-Hu \& Moon, 2011), no previous meta-analytic studies had explored the differences among grade levels.

Interpretation of the findings from this study needs to consider problems of defining enrichment programs in the research literature. Many studies included in this meta-analysis did not describe detailed characteristics of programs in terms of enrichment program definition, types of intervention, detailed participants' demographic information, and duration of programs. This caused difficulties for inclusion decisions for this meta-analysis and for coding of the studies. Although the idea that enrichment programs have a positive influence on students' academic achievement and socio-emotional development is appealing, there are still questions 
remaining about how different environment and population characteristics (e.g., school context, SES, ethnicity, gender, program duration, different types of intervention, teacher training) influence on the effects of enrichment programs. Researchers in gifted education need to understand the importance of describing detailed information about their programs, such as population, program specification, and intervention specification so that practitioners can replicate studied programs and other researchers can replicate their studies.

However, more studies ( 8 studies) examined the effects of enrichment programs on socio-emotional development of high school gifted students. Many enrichment programs for high school gifted students examined career goals and motivation more than specific academic achievements and demonstrated positive effects on socio-emotional outcomes, which include career goal setting and career aspirations. High school students become aware of their internal goals and start to narrow down their career choices (Gottfredson, 1996; Kim, 2010). Therefore, high school gifted students might happen to participate in academic programs that fit into their future career goals, which leads them to demonstrate the highest influence on their academic achievement.

Findings of this meta-analysis show that enrichment programs influence middle school students the most in socio-emotional development. This result supports the view that adolescence is a time of personal growth and social dimensions become increasingly important facilitators and inhibitors of talent development (Dixon \& Moon, 2006). Interventions on social domain along with peer group may impact talent development trajectories of gifted adolescence because peer relationships are tremendously important to adolescents (Coleman, 2001). Gifted students tend to be more mature than their age peers and tend to have issues related to the gap between their educational development level and educational environment in school (Robinson, 
2008). Social networks and social supports are important elements for gifted students, and enrichment programs provide unique experiences with academically challenging coursework and social support from gifted peers, which allow students to express their capabilities more in enrichment programs than in regular school classes (Olszewski-Kubilius \& Lee, 2004). Gifted students in middle school grades can benefit from enrichment programs for their socio-emotional outcomes. Middle school gifted students are in the early developmental stages of adolescence, and start to make many critical life decisions related to future career paths (Dixon \& Moon, 2006). Therefore, personal growth in middle-school-age students is important, along with positive social relationships. Supporting gifted students by offering access to enriched and advanced coursework with peers helps students set their goals for the future and make a commitment to achieving those goals. Enrichment programs can provide challenging academic content within their interest areas, along with peer groups.

In terms of types of programs, summer residential programs demonstrated the highest impact on gifted students' academic achievement as well as on socio-emotional development. However, only one effect size each for a summer day program and a summer residential program explained the impact of academic achievement for gifted students; therefore, additional care should be taken to interpret these results about the influence of enrichment programs on academic achievement based on types of programs.

For socio-emotional outcomes, summer residential programs may provide more diverse interactions among peers and more diverse activities than academic-year programs or than summer day programs. Also, summer programs may have more flexible and more numerous options in academic content than academic-year school programs and students choose to be in specific summer programs so that they typically display more commitment in the summer 
programs. Peer groups in programs provide a basis for adolescents to determine their own levels of competence in academic, social, and physical domains, and summer residential programs provide opportunities for gifted students to be with peers through various social activities (Rinn, Reynolds, \& McQueen, 2011).

The results of this study demonstrated that continuous interventions throughout the academic year are also effective for gifted students' academic achievement. Goldring (1990) suggested that special classes beyond regular school classes benefit gifted students in terms of academic achievement, and this study suggests that the interventions need to be continuous in order to maximize the program effects.

\section{Limitations and Conclusions}

Like many other studies, this meta-analysis has limitations. First, the number of usable empirical studies for this meta-analysis was much smaller than expected for the voluminous body of literature related to the effects of enrichment programs specifically. This limitation is closely related to the existing situation in the enrichment program research literature. Many studies were not clear about definitions of the enrichment program intervention they examined, nor did they gave detailed description of their practices. Therefore, there should be some caution in interpreting the results from this meta-analysis.

Second, this meta-analysis examined effects of enrichment programs with two outcomes of academic achievement and socio-emotional development; however, there are more variables that can be examined within each of outcome variables. For example, studying different subject areas or different types of outcome measurements within academic achievement outcomes or specific areas of socio-emotional development within socio-emotional development outcomes would be valuable information for future research and practices. 
Third, this meta-analysis did not include qualitative studies, which do not include the quantitative information needed for a meta-analysis. In the future, synthesized studies, including both qualitative and quantitative information, would be valuable to provide a more comprehensive understanding related to effects of enrichment programs.

Fourth, this study synthesized two different designs of studies, pre-post comparison with a single group and treatment and control group comparisons. This study explored different study designs as a moderator and demonstrated that the type of study influenced effect sizes in socioemotional development. Therefore, there should be some caution in interpreting the results from this meta-analysis on socio-emotional development. Finally, not many studies described characteristics of participants, including gender, SES, rural or urban, or school context. For this reason, this meta-analysis does not imply all of the potential information that the studies could provide. Future research and evaluation studies should document detailed information to allow for replication of their successful program implementation. Dai, Swanson, and Cheng (2011) explored the state of research on giftedness and suggested that more research needs to be done to make connections between conceptual areas and paradigmatic practices. Systematic documentation through research and evaluation would provide evidence for the effects of enrichment programs so that policy makers and educators will support enrichment programs for gifted students.

Despite limitations of this meta-analysis, this study makes contributions to the field of gifted education in several ways. First, the findings from this meta-analysis support the positive effects of enrichment programs on gifted students in terms of academic achievement and socioemotional development. Second, this meta-analysis has updated previous synthesized research on the effects of enrichment programs. There has been no current meta-analytic study focusing on 
enrichment programs, so this study provides research-based information on enrichment programs for practitioners in different grade levels. Also, there has been no study synthesizing effects of different program types on enrichment programs. Third, this study suggests that more empirical research, which includes more specifics about their enrichment programs, are needed in the field of gifted education. In summary, although previous literature has explored the effects of enrichment programs, this study provided new information and supported previous literature that can benefit researchers and practitioners. 


\section{References}

Asher, W. (1986). Conducting research with meta-analysis: A new direction for gifted education. Gifted Child Quarterly, 30, 7-10.

Asher, W. (2003). Meta-analysis and gifted education. Journal for the Education of the Gifted, 27, 7-19.

Borenstein, M., Hedges, L. V., Higgins, J. P. T., \& Rothstein, H. R. (2006). Comprehensive Meta-Analysis (Version 2) [Computer software]. Englewood, NJ: Biostat.

Borenstein, M., Hedges, L. V., Higgins, J. P. T., \& Rothstein, H. R. (2009). Introduction to metaanalysis. Hoboken, NJ: John Wiley \& Sons, Ltd.

Clark, B. (2013). Growing up gifted (8th ed.). Boston, MA: Pearson.

Coleman, M. R. (2001), Surviving or thriving? Gifted Child Today, 24(3), 56-63.

Cooper, H. (1998). Synthesizing research (3rd ed.). Thousand Oaks, CA: Sage.

Cooper, H. (2010). Research synthesis and meta-analysis (4th ed.). Thousand Oaks, CA: Sage.

Cooper, H., Charlton, K., Valentine, J. C., Muhlenbruck, L., \& Borman, G. D. (2000). Making the most of summer school: A meta-analytic and narrative review. Monographs of the Society for Research in Child Development, 65(1),1-127. Retrieved from http://www.jstor.org/stable/3181549

Cross, T. L. \& Cross, J. R. (Eds.) (2012). Handbook for counselors serving students with gifts and talents: Development, relationships, school issues, and counseling needs/interventions. Waco, TX: Prufrock Press. 
Dai, D. Y., Swanson, J. A., \& Cheng, H. (2011). State of research on giftedness and gifted education: A survey of empirical studies published during 1998-2010 (April). Gifted Child Quarterly, 55, 126-138. doi:10.1177/0016986210397831

Davis, G., Rimm, S., \& Siegle, D. (2011). Education of the gifted and talented (6th ed.). Boston, MA: Pearson.

Dixon, F. A. \& Moon, S. M. (2006). The handbook of secondary gifted education. Waco, TX: Prufrock Press.

Ellis, P. D. (2011). The essential guide to the interpretation of research results. Cambridge, UK: Cambridge University Press.

Fan, X., \& Chen, M. (2001). Parental involvement and students' academic achievement: A metaanalysis. Educational Psychology Review, 13(1), 1-22.

Fiddyment, G. E. (2014). Implementing enrichment cluster in elementary schools: Lessons learned. Gifted Child Quarterly, 58, 287-296. Doi: 10.11770016986214547635

Fox, L. H. (1979) Educational acceleration of intellectually talented youths: Prolonged discussion by a varied group of professionals - Sexism, democracy, and the acceleration versus enrichment controversy. In W. C. George, S. J. Cohn \& J. C. Stanley (Eds.), Educating the gifted: Acceleration and enrichment, revised and expanded proceedings of the Ninth Annual Hyman Blumberg Symposium on Research in Early Childhood Education. London, UK; John Hopkins University Press Ltd.

Gardner, H. (1983). Frames of mind: The theory of multiple intelligences. New York, NY: Basic Books. 
Goldring, E. B. (1990). Assessing the status of information on classroom organizational frameworks for gifted students. Journal of Educational Research, 83, 313-326.

Goleman, D. (1995). Emotional intelligence. New York, NY: Bantam Books.

Gottfredson, L. S. (1996). Gottfredson's theory of circumscription and compromise. In D. Brown, L. Brooks, \& Associates (Eds.), Career choice and development (3rd ed., pp. 179-232). San Francisco, CA: Jossey-Bass.

Hébert, T. P. (2011). Understanding the social and emotional lives of gifted students. Waco, TX: Prufrock Press.

Hynes, K., O’Connor, S., \& Chung, A. M. (1999). Literacy: Exploring strategies to enhance learning in after-school programs. Boston, MA: Wellesley College Center for Research on Women. (ERIC Document Reproduction Service No. ED 438045)

Kim, M. (2010). Preferences of high achieving high school students in their career development. Gifted and Talented International, 25, 66-74.

Kulik J. A. (1992). An analysis of the research on ability grouping: Historical and contemporary perspectives. Storrs, CT: National Research Center on the Gifted and Talented.

Kulik, J. A., \& Kulik, C. C. (1984). Effects of accelerated instruction on students. Review of Educational Research, 54, 409-425.

Lee, S.-Y., Matthews, M., \& Olszewski-Kubilius, P. (2008). A national picture of talent search and talent search educational programs. Gifted Child Quarterly, 52(1), 55-69. doi: $10.1080 / 02783193.2010 .485301$

Lee, S.-Y., Olszewski-Kubilius, P., \& Peternel, P. (2010). Achievement after participation in a preparatory program for verbally talented students. Roeper Review, 32, 150-163. doi: 10.11770016986207311152 
Lynch, S., \& Mills, C. J. (1990). The skills reinforcement project (SRP): An academic program for high potential minority youth. Journal for the Education of the Gifted, 13, 364-379, doi:10.1177/016235329001300406

Markowitz, D. Z. (2004). Evaluation of the long-term impact of a university high school summer science program on students' interest and perceived abilities in science. Journal of Science Education and Technology, 13, 395-407.

Miller, R., \& Gentry, M., (2010). Developing talents among high-potential students from lowincome families in an out-of-school enrichment program. Journal of Advanced Academics, 21, 594-627.

Olszewski-Kubilius, P., \& Lee, S. (2004). Parent perceptions of the effects of the Saturday enrichment program on gifted students' talent development. Roeper Review, 26(3), 156165.

Olszewski-Kubilius, P. \& Limburg-Weber, L. (1999). Options for middle school and secondary level gifted students. Journal of Secondary Gifted Education, 11(1), 4-10.

Plucker, J., \& Callahan, C. M. (Eds.) (2014). Critical issues and practices in gifted education: What the research says (2nd ed.). Waco, TX: Prufrock Press.

Reis, S. M., \& Boeve, H. (2009). How academically gifted elementary, urban students respond to challenge in an enriched, differentiated reading program. Journal for the Education of the Gifted, 33(2), 203-240.

Renzulli, J. S., \& Reis, S. M. (1997). The Schoolwide Enrichment Model: A how-to guide for educational excellence (2nd ed.). Mansfield, CT: Creative Learning Press.

Rinn, A., Reynolds, M. J., \& McQueen, K. S. (2011). Perceived social support and the selfconcepts of gifted adolescents. Journal for the Education of the Gifted, 34(3), 367-369. 
Robinson, N. M. (2008). The social world of gifted children and youth. In S. I. Pfeiffer (Ed.), Handbook of giftedness in children: Psychoeducational theory, research, and best practices (pp. 33-51). New York, NY: Springer.

Rosenthal, R. (1991). Meta-analytic procedures for social research. Newbury Park, CA: Sage Publications.

Schacter, J. (2001). Reducing social inequality in elementary school reading achievement: establishing summer literacy day camps for disadvantaged children. Santa Monica, CA: Milken Family Foundation. Retrieved from http://www.mff.org/pubs/reading_camp_study2001.pdf

Schiever, S. W. \& Maker, C. J. (2003). New directions in enrichment and acceleration. In N. Colangelo \& G. A. Davis (Eds.), Handbook of gifted education (3rd ed., pp. 163-173). Boston, MA: Allyn \& Bacon.

Stake, J. E., \& Mares, K. R. (2001). Science enrichment programs for gifted high school girls and boys: Predictors of program impact on science confidence and motivation. Journal of Research in Science Teaching, 38(10), 1065-1088. doi:10.1002/tea.10001

Steenbergen-Hu, S. \& Moon, S. M. (2011). The effects of acceleration on high-ability learners: A meta-analysis. Gifted Child Quarterly, 55(1), 39-53. doi:10.11770016986210383155

Vaughn, V. L., Feldhusen, J. F., \& Asher, J. W. (1991). Meta-analyses and review of research o pull-out programs in gifted education. Gifted Child Quarterly, 35(2), 92-98.

Walsh, R. L., Kemp, C. R., Hodge, K. A., \& Bowes, J. M. (2012). Searching for evidence-based practice: A review of the research on education interventions for intellectually gifted 
children in the early childhood years. Journal for the Education of the Gifted, 35, 103128.

Warner, R. M. (2008). Applied statistics: From bivariate through multivariate techniques. Newbury Park, CA: Sage Publications. 
